\title{
Practice and Key Technologies of Integration and Sharing of Water Resources and Data Resources Based on Cloud Computing
}

\author{
Fang Li, ${ }^{1}$ Luofeng Xie, ${ }^{2}$ and Weidong Huang $\mathbb{D}^{3}$ \\ ${ }^{1}$ Office of Educational Administration, Lanzhou University of Resources and Environment, Lanzhou 730021, China \\ ${ }^{2}$ Department of Hydraulic Engineering, Nanjing Hydraulic Research Institute, Nanjing 210000, China \\ ${ }^{3}$ Hydrology and Water Resources Bureau of Gansu Province, Lanzhou 730000, China \\ Correspondence should be addressed to Weidong Huang; gsdxhwd@163.com
}

Received 3 January 2022; Revised 19 January 2022; Accepted 20 January 2022; Published 18 February 2022

Academic Editor: Xin Ning

Copyright (c) 2022 Fang Li et al. This is an open access article distributed under the Creative Commons Attribution License, which permits unrestricted use, distribution, and reproduction in any medium, provided the original work is properly cited.

\begin{abstract}
The study of how to construct the integration mode of water conservancy information resources for water conservancy applications is extremely practical. This paper discusses the history of cloud computing and data centers, as well as the development paths of related technologies, and proposes the use of cloud computing to integrate and share water conservation data resources. The current state of water conservation informatization, as well as its characteristics and future development trends, is investigated. The regional water conservancy integrated management system is analyzed in detail according to the process and ideas of software project design and development, and the overall architecture model based on cloud computing is determined by analyzing relevant regulations of water conservancy informatization infrastructure and the actual situation of water conservancy informatization construction in sample areas. And the system's specific functions are designed and presented. This method has changed the traditional concept and mode of water conservation business management, and it can achieve service value-added and efficient and low-cost development and utilization of information resources, according to practice.
\end{abstract}

\section{Introduction}

In recent years, China's investment in water conservancy informatization is very huge, and water conservancy informatization has made great progress [1]. With the rapid development of water conservancy informatization, water conservancy-related information systems at all levels have produced huge amounts of water conservancy-related information and data [2]. Although these information and data have played a great role in water conservancy development, decision-making, management, and service, these data have not fundamentally formed resources that can be further utilized. With the continued development of the national economy and society, the demand for water conservation administrative management is increasing, the demand for comprehensive analysis and decision support in water conservation business applications is increasing, and the demand for the integration and sharing of water conservation information resources is increasing [3]. The effective integration and sharing of water conservancy information resources cannot be realized at this stage due to the development level and mode of water conservancy informatization, the entire water conservancy management system, regional differences, technology application, and informatization environment [4]. The study of how to construct the integration mode of water conservancy information resources for water conservancy applications is of great practical importance [5]. Using new technologies such as cloud computing, Internet of Things, mobile Internet, big data, intelligence, blockchain, etc., building integration and sharing projects of water conservancy data resources and accelerating the sharing and exchange of water conservancy data resources are the key contents of water conservancy informatization construction.

With the rapid development and application of information technology, various industries have accumulated a lot of information technology resources. Water conservancy industry, like other industries, after years of construction, 
has achieved some construction achievements and played an important role in water conservancy management [6]. The national water conservancy informatization has entered a period of rapid development with the comprehensive promotion of key projects, continuous improvement of infrastructure, continuous deepening of business applications, significant strengthening of security environment, and gradual development of resource integration [7]. With the overall speed-up of information technology and water conservancy business, various complex climatic conditions and business collaboration are increasingly dependent on information resources and technology. Single-point information construction, although solving specific business needs, operates independently with various business systems, forming an information island [8]. Each department invested in the construction of software and hardware resources, resulting in scattered business systems and software and hardware resources, forming an isolated island with the boundaries of regions, specialties, departments, and systems. The security and stability of various systems are not high, and it is difficult to provide high-quality services to external users, which objectively forms a resource sharing gap [9]. These problems lead to insufficient, reasonable, and effective utilization of information resources, which leads to repeated construction and waste of funds from time to time and limits the development of water conservancy informatization. For water conservancy departments, the informatization process also faces the problems of imperfect infrastructure and lack of professionals. Therefore, the concept of water resources integration and sharing system based on cloud computing architecture is put forward. Cloud computing, big data, mobile Internet, and other technologies are used to realize resource integration and business collaboration, so as to better serve water conservancy business management.

The application of cloud computing technology has fundamentally changed the management and service mode of water conservancy informatization in China, provided new ideas for the integration and sharing of resources and information in China's water conservancy industry, and provided new impetus for the informatization construction of China's water conservancy industry [10]. Therefore, the application of cloud computing in China's water conservancy informatization construction is helpful in promoting the transformation from "digital water conservancy" to "smart water conservancy," and it is also an inevitable requirement for the integration and sharing of water conservancy information resources in China [11]. The integration of water conservancy information resources is a process of combing, classifying, organizing, and standardizing water conservancy business and information resources for the purpose of sharing, so as to meet the demand of water conservancy business cooperation for water conservancy information resources sharing [12]. It is not only a process of information technology integration, but more importantly, a process of establishing sharing mechanism and rules of water conservancy information resources. At the same time, the integration of water conservancy information resources reflects the relevance between water conservancy information resources and water conservancy business, so as to meet the needs of water conservancy business collaboration for information resource sharing. The rapid development of cloud computing technology has provided strong technical support for China's water conservancy informatization construction [13]. Although China's water conservancy informatization construction has made some progress, it still faces many problems. Therefore, it is of great practical significance to study the characteristics of cloud computing application in water conservancy industry, the shortcomings in water conservancy informatization construction, and how to build a scientific and efficient water conservancy cloud platform. In this paper, cloud computing is used to realize the integration and sharing of water conservancy information resources, and information resources are transformed into information services, which are provided to water conservancy departments, the public, and specific organizational users. This method can realize value-added services and efficient and low-cost development and utilization of information resources.

\section{Related Work}

Based on the principles and characteristics of cloud computing, literature [14] analyzes the problems faced by cloud computing in water conservancy information construction and puts forward the scheme of scientifically constructing water conservancy cloud platform. And clarify the strategy of cloud computing in water conservancy information construction, build a convenient, efficient, and safe water conservancy information cloud system, make the integration and sharing of information resources, and promote the development of water conservancy information. Literature [15] believes that the investment in water conservancy informatization is huge in recent years, and the state and local governments attach great importance to water conservancy informatization. However, due to various reasons, there are still some universal problems in the process of water conservancy informatization. Only the introduction of water conservancy "cloud computing" platform and water conservancy big data analysis platform can better develop and utilize resources. Literature [16] analyzes and models the water resources scheduling problem and introduces the related technology of ant colony algorithm to solve the problems in water resources scheduling. According to the shortcomings of ant colony algorithm, the ant colony algorithm is improved, and the relevant knowledge of genetic algorithm is introduced into the traditional ant colony algorithm, which makes up for the problems of insufficient node pheromone and slow update in the initial stage. In order to analyze the water resources integration mechanism in more detail, literature [17] separately proposed the virtual machine resource integration in the resource management based on energy efficiency. The multivirtual machine migration scenario is analyzed and studied from many different angles, and three integration mechanisms are proposed. Literature [18] combines cloud computing with water conservancy and Hydropower Engineering, integrates the information of water 
conservancy and Hydropower Engineering Information Model in each stage of the project through BIM's threedimensional digitization technology, information exchange standard, data storage and access technology, and information integration technology, and forms the information model as the carrier of engineering data information. Literature [19] analyzes the current situation of the construction and development of water conservancy information resources, the problems affecting the processing and application of data resources, and the necessity of data resource integration. Literature [20] describes the background knowledge of water resources dispatching and introduces the classification and common dispatching methods in water resources dispatching at present. Literature [21] distributed integrated data retrieval engine and unified resource discovery platform based on SolrCloud. This study is also a useful exploration to promote the integration and sharing of water conservancy information resources. Literature [22] developed and designed the water resources integration mechanism based on the OpenStack open source cloud platform. The module function and logical interface of energy aware resource integration smart cloud platform based on OpenStack are designed. Real-time monitoring data is required for the design and implementation of integration mechanisms. Three common data center monitoring systems are examined and introduced in literature [23]. It also examines and sums up the growth of data center power monitoring and management, as well as virtual machine monitoring. Finally, two improvements to data center monitoring are proposed. According to literature [24], we should not only realize the unified deployment of water conservancy data, but also standardize and guide the construction of application projects by establishing an integrated, flexible, and scalable integration scheme by using cloud computing mode and database object-oriented modeling method. The feasibility and necessity of using data warehouse technology to integrate water resources are discussed in literature [25]. Some key technical issues with technology application are examined, and some technology application suggestions are made. According to the literature [26], the big data of the water conservation and hydropower project information model is analyzed, processed, and stored in modules using cloud computing, and then the data information standards and exchange standards are unified to form a virtual database center of the water conservation and hydropower project, providing a shared operation and management platform for all project participants. It can effectively realize information sharing of the information model at each stage of the project, laying the groundwork for BIM Technology's deep application. Literature [27] constructs an intelligent monitoring BIM cloud platform for a water conservancy project using cloud computing and other technologies to analyze, process, and store the big data of water conservancy and hydropower project information model in modules and uses cloud computing and other technologies to do so. It provides all project participants with a shared operation and management platform, effectively resolving the problems of information loss and information island at each stage of the water conservation and hydropower project.

Aiming at the problems faced in the development and utilization of water conservancy business related information resources in the process of water conservancy informatization, this paper constructs a water conservancy information resource integration model and analyzes water conservancy information resource management. On this basis, the "cloud service" integration model of water conservancy information resources is constructed. By transforming the traditional low-efficiency and multilevel "small data" working mode into high-efficiency and nonlevel "big data" interactive mode, cloud computing and water conservancy business will be integrated as a whole. Form an information environment with extensive perception, data concentration, resource sharing, comprehensive information, and diversified services. Realize continuous monitoring, forecasting, early warning, and information service for management and service objects from day to day, breaking the information island, realizing the orderly sharing of information, forming an environment of rich information resources and data sharing, and fundamentally changing the traditional water conservancy business management concept and mode.

\section{Methodology}

3.1. Cloud Computing and Cloud Computing-Oriented Data Center. In recent years, with the rapid development of information technology and the wide application of new technologies [28], new changes have been brought to society. Emerging technologies such as cloud computing, Internet of Things, mobile Internet, and big data are profoundly affecting the development of various social industries. Ubiquitous perception, virtualized resources, knowledge-based processing, intelligent management, and other new technologies have significantly improved the informatization level of society. As a traditional industry of water conservancy, the overall informatization level is not high. At present, most of the water conservancy informatization systems are mainly aimed at meeting the business application of their respective departments, with single business function and lack of overall unified standards, which makes it difficult to realize resource integration and business collaboration across departments and businesses.

Cloud is an image of the Internet, and cloud computing is a brand-new computing and service model, which refers to the process of integrating and processing huge data and information resources with the help of Internet technology, and sending the processing results to users through servers according to users' needs [29]. Cloud platform makes resources highly shared, which greatly improves the efficiency of software and hardware. Therefore, cloud computing can efficiently and quickly process massive amounts of information in a very short time. The main structures of cloud computing are data resources, big data processing, and terminal processing. 
End users can choose different computing service levels such as hardware resources, platforms, or software resources based on their business needs in the cloud computing mode, without taking into account the cloud's computing capacity, storage capacity, or load capacity, and the cloud handles everything. The utilization rate of resources can be greatly increased using this computing mode, and management can be done at a low cost and with high efficiency. After homogenization by virtualization technology, the goal of cloud computing is to distribute server resources to users flexibly. CPU, memory, network bandwidth, and other virtualized computing resources are among them. With the continued reduction in the price of solid-state storage devices and the widespread adoption of network-attached storage technology, storage space allocation and use havebecome extremely flexible, and it has gradually evolved into a separate problem that no longer belongs to computing resources. The cloud computing system's redundancy and distributed storage of hardware and software data ensure data reliability, and data can still be used even if a part of the system fails.

Big data technology is an information technology developed according to the characteristics of big data, which can realize fine and dynamic data analysis of multisource, multidimensional, massive, and polymorphic water conservancy data, so as to meet the needs of large-scale storage, organization, mining, and application of modern water conservancy data, and thus improve the decision support ability of water conservancy affairs and business. The "cloud service" model of water resources is shown in Figure 1. Based on different levels of water resources management, the corresponding information resources are integrated to form four platforms for infrastructure, data services, platform services, and application services. The platforms, respectively, correspond to hardware infrastructure, software infrastructure, information, and services in water conservancy information resources.

The water conservancy industry has accumulated a large number of abundant data resources in the process of informatization development. Using big data technology, the data of various water conservancy elements and flood data (such as real-time water and rain data, real-time work data, and water demand monitoring data) are digitized, reorganized, gathered, and stored according to the characteristics and requirements of water conservancy industry and then refined and counted according to data classification and usage rules, so as to realize data reconstruction. Then, tap the potential information of these data, refine the thematic information base, and provide advanced, scientific, and efficient data services for the management system.

3.2. Data Integration and Sharing. The content of integration and sharing is mainly to support the work data resources, business systems, and basic software and hardware resources of each unit, and at the same time to establish a scientific sharing mechanism and process. Water conservancy information resources include all kinds of structures, levels, and services generated by water conservancy government affairs and business processes. Through the integration of information resources, efficient utilization, specialized application, and intensive service of water conservancy information resources can be completed.

The physical deployment environment of data resources is migrated to the integrated unified basic software and hardware platform, and the data resources are placed in the unified business data storage area, which is known as integration by source aggregation. The unified semantic space is then centrally stored in the data warehouse of the business data storage area, and the organic data system is integrated, which is subject-oriented, object-oriented, unified semantic, easy to share, easy to associate, and easy to mine after conversion according to the basic database of water conservancy, specialized database of water conservancy, and object-oriented model. Metadata is extracted, while a data resource catalog is created at the same time. The resource integration and sharing platform only carries the sharing load of the centralized data resource catalog, not the sharing load of specific data, and the specific supply mode is negotiated by both parties. To meet various forms of metadata retrieval requirements, index and maintain various types of data, including working condition object metadata, analyze unified discovery platform user retrieval requests, and retrieve corresponding catalog information from metadata index database, metadata registration, storage, and retrieval modules must form distributed retrieval of water conservancy information one by one. The construction scheme is shown in Figure 2.

The data management and maintenance system can manage and maintain all kinds of data in the data subcenter. Application integration and sharing is to build a unified comprehensive application, which organically integrates completely different application software and systems based on different platforms and with different schemes into a seamless, parallel, and easy-to-access single system and makes them conduct business processing and information sharing as a whole. The water conservancy application integration and sharing technology mainly includes two aspects: supporting platform sharing and unified portal integration.

Based on the management needs of water conservancy business and affairs, information resource planning establishes the information model of application system, including the model of system function, data, and architecture, through the demand analysis of selected functional areas. And plan the required data resources, and define the methods of data resource acquisition, transmission, storage, exchange, sharing, and application. Data source synchronization integration means that when data resources are integrated, data sources remain unchanged; that is, data resources are not migrated in physical deployment environment. Data integration stores a data image library in the business data storage area by means of data synchronization. Then, it is processed into the data warehouse according to the unified rules. Before sharing, it is necessary to establish the management mechanism of data sharing and exchange, standardize the process of data supply and use, and ensure the quality of shared and exchanged data. In the process of 


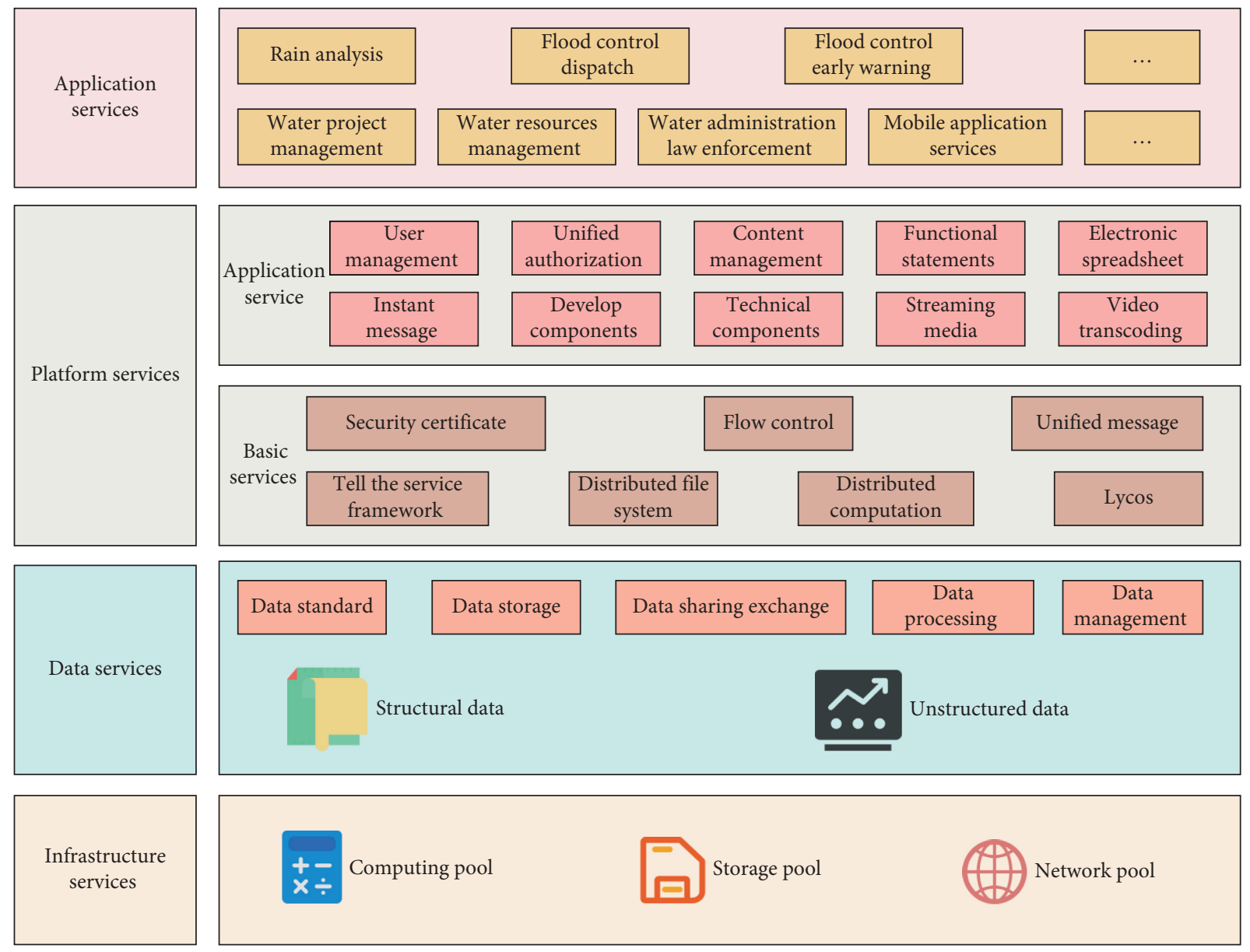

FIGURE 1: Cloud service model of water resources.

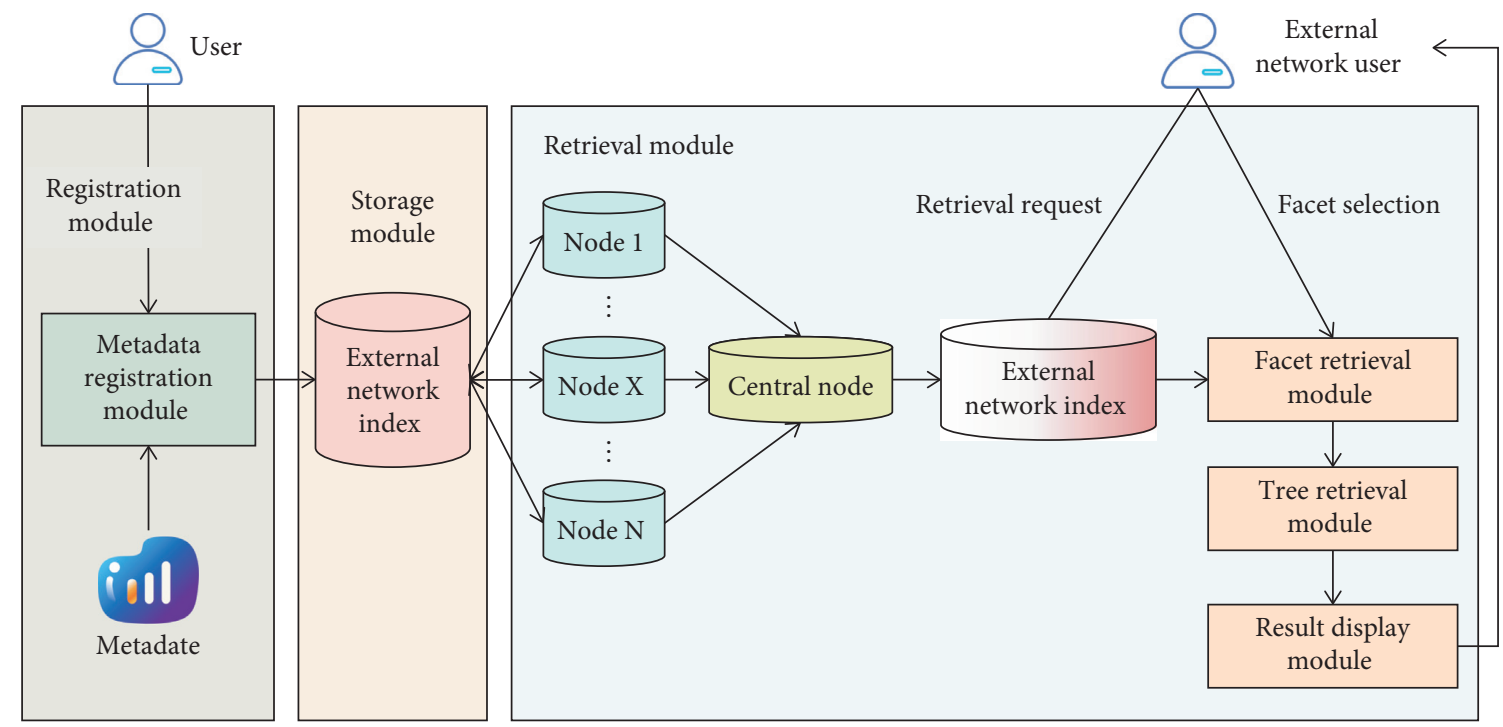

FIgURE 2: Construction scheme of information storage and retrieval.

sharing, it is also necessary to monitor the exchange sharing situation in real time, so as to improve the efficiency and management level of sharing and exchange services.
3.3. Research and Practice of Water Resources Integration and Sharing Technology. It is necessary to fully combine the characteristics of the water conservancy industry, base overall plans on the current situation of China's water 
conservancy industry, set up a water conservancy information cloud system scientifically and rationally, place a premium on the quality of cloud services, and promote the development of water conservancy informatization in China during the process of building water conservancy informatization based on cloud computing. Data sharing and access control services, water conservancy spatial data management and query, and other functions of this system support the information sharing and collaborative office of government departments and water conservancy units. Provide unified services for various government departments and professional water conservancy application systems, as well as an integrated management platform for water conservancy information resources, including water conservancy spatial information.

Let us assume a water resources network with $n$ reservoirs. We assume that the dispatching aims at the maximum annual power generation and that the power generation is $E$, and then,

$$
E=\frac{1}{n} \sum_{i=1} \sum_{j=1} E_{i, j}
$$

where $n$ is the number of years. State transition rule setting:

$$
\begin{gathered}
V_{i, j}+1=V_{i, t}+I_{i, t}-R_{i, t}-\operatorname{Los}_{i, t}, \\
V_{\min , i, t} \leq V_{i, t} \leq V_{\max , i, t}, \\
V_{\min , i, t+1} \leq V_{i, t+1} \leq V_{\max , i, t+1} .
\end{gathered}
$$

For a reservoir, its objective function is set as follows:

$\min F=\sum_{i=1} \sum_{i=1} w *[q(t)+S * Q(t)]^{2}+\left[\sum_{i=1} q(t)+\sum_{i=1} Q(t)\right]$

Among them, $T$ is the period of the scheduling cycle, and the total scheduling time is divided into several periods with the size of T. $q(t)$ is the outflow of a reservoir in the Tperiod. $Q(t)$ is the flow process of a reservoir from the current state to the safe water level of storage capacity. $\sum_{i=1} Q(t)$ is the process that all reservoirs reach their own safe water level. $S$ and $W$ represent the reliability coefficient and harmonic parameters of the reservoir, respectively. Through the operation of the algorithm, we finally get the optimal solution of the objective function, that is, the optimal scheduling scheme.

Realize centralized data management, unified system information release, and one-stop business processing. Simultaneously, it integrates existing business systems' access control and provides centralized access to original business applications via single sign-on. Collect and provide external services based on standardized data on working conditions. Specifically, each pumping station's operating condition data must be normalized using the pumping station operation data normalization technology, the normalized data must be stored in the reorganization database, and the data must be recorded using the WebService interface provided by the engineering monitoring intranet platform. The working condition object metadata is created and stored in the intranet platform's metadata database based on the object model. Following integration, key technologies for real-time operation state evaluation of pumping stations can be provided with the necessary data access services via various types of query WebService interfaces.

Assuming that the number of individuals in the population is $n$, we use $g_{\max }$ to represent the function value of the individual with the greatest fitness in the current population and use $g_{0}$ to represent the average value of the fitness function of all individuals in the current population, which is

$$
g_{0}=\frac{\left(g_{1}+g_{2}+\cdots+g_{n}\right)}{n} .
$$

Let $p_{c}$ denote the crossover operator. $g$ represents the fitness of the individual with a relatively large fitness function value among the two individuals participating in the crossover. Therefore, we get the following calculation formula for the crossover operator:

$$
p_{c}=\left\{\begin{array}{l}
k_{1} \frac{g_{\max }-g}{g_{\max }-g_{0}}, \quad g \geq g_{0}, \\
k_{2}, \quad g \leq g_{0} .
\end{array}\right.
$$

Water conservancy projects, water resources development and utilization, water conservancy construction projects, real-time flood information, social, economic, demographic, and spatial geography, and other related contents are among the system data requirements, according to the analysis of business functions. Collect widely dispersed water conservation data, integrate water conservation data resources, integrate, supplement, and improve the construction of a number of critically needed public basic databases, and integrate and build professional databases using database construction standards and business application systems. To create a perfect dynamic energy efficiency management mechanism and test its results, we must first create a reasonable dynamic power model of the server, from which we can derive the server's real-time power using existing real-time system parameters. It demonstrates that CPU utilization and total server power are closely related, with total server power increasing linearly as CPU utilization rises. Its growth range is between the server's idle power and peak power. Through systematic research and analysis, this relationship is described by the following mathematical expression:

$$
P(u)=P_{\text {idle }}+\left(P_{\text {busy }}-P_{\text {idle }}\right) * u .
$$

Among them, $P(u)$ represents power, $P_{\text {idle }}$ represents the power when the server is idle, $P_{\text {busy }}$ represents the power when the server is working at full load, that is, the peak power, and $u$ refers to the real-time utilization of the CPU. Another empirical nonlinear model is mathematically expressed as follows: 


$$
P(u)=P_{\text {idle }}+\left(P_{\text {busy }}-P_{\text {idle }}\right) \cdot\left(2 u-u^{r}\right) .
$$

$R$ is the minimum variance calibration parameter, which needs to be obtained through a series of standard experiments for different types of servers. The above model is verified by repeatedly measuring the power of thousands of physical machines under various loads, and the results are shown in Figure 3.

The experimental results fully prove that the linear model results are quite different from the measured power, and the empirical model and the measured power are almost mild. This experimental result can also explain the fact that $\mathrm{CPU}$ is the main power using component in the server, and the dynamic power range of other components is relatively small.

A distributed index of metadata information of various types of working conditions and dispatching among pump stations is established in the internal and external networks. Based on the index sharing mechanism, the object metadata information of the data compiled by the internal network is provided to the external network platform through the gateway between the internal and external networks. The specific granularity and exchange frequency need to be determined according to the service objects of the external network platform, including ordinary access users, data managers of the dispatching sharing platform, and the specific use requirements of key technologies for monitoring and feedback of the operation and dispatching performance of pumping stations. In order to meet the demands of data sharing service and service for the public in various business application systems of the city's water system, the system must have large data storage capacity, high data processing and service capacity, high reliable data storage security guarantee conditions, and timely disaster recovery capacity.

The centralized data is integrated by data source aggregation and data source synchronization, the data sharing load is carried by the resource integration and sharing platform, and the internal and external exchange and sharing of data are realized by the data authorized access and data exchange platform. The data demander is responsible for querying, browsing, and sharing application of data resources, the data source responsible unit is responsible for completing the application approval of data resources sharing, and the information center is responsible for system function maintenance and technical support of data resources sharing. Data collection and entry mainly completes the automatic collection of business system and e-government system data. According to different data sources, the system has designed corresponding collection and entry programs to realize the automation of data entry to the greatest extent and reduce the workload of data storage. Data collection and entry technology realizes the automatic collection of dynamic data of each application system.

\section{Result Analysis and Discussion}

The system's foundation is data. Data is centralized in the data center for unified storage and management, and data services are provided to the outside through the data

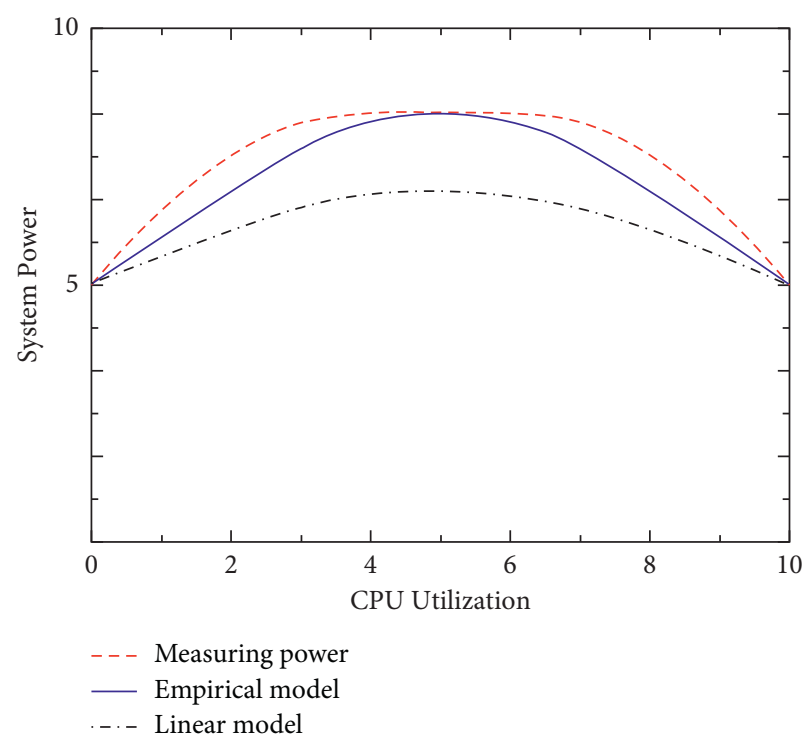

FIgure 3: Comparison between model and measured power.

interface, ensuring data security. The data is now independent, and it has a fully supported mechanism for concurrency control, access control, data backup, and security recovery thanks to the data center. It implements a database redundancy architecture, creates a cloud data center and a local synchronous storage method, and creates a masterbackup mechanism to ensure data security all at the same time. Early warning principles are developed by the system: for water supply, the system design early warning lines are yellow, orange, and red. The following are the meanings of the three warning lines: (1) the lowest level is yellow. Above the warning line, the reservoir should be able to provide water to both urban and rural areas, as well as irrigation water. (2) Orange is a medium difficulty level. The reservoir should be above the warning line to ensure urban and rural water supply while restricting irrigation water. The highest level is (3) red. The reservoir should ensure urban and rural water supply and suspend other water use above the warning line. Figure 4 depicts the water supply warning line for key reservoirs.

The integrated data of flood control and drought relief, safe drinking water in rural areas, real-time water and rain conditions, water resources, irrigation and drainage pumping stations, etc. are correlated and analyzed, and the main and special databases are constructed. Combined with the characteristics of time series changes, a data warehouse based on the relationship of data professional model is preliminarily established to carry out deep mining and analysis applications. Focusing on the work of the water conservancy center, relevant data analysis work is carried out in the aspects of water resources monitoring and evaluation, meteorological early warning and forecasting, flood and drought disaster monitoring and early warning, flood control dispatching decision-making, dynamic monitoring and analysis of soil erosion, etc., and a large amount of valuable unknown information is analyzed and excavated from the known, historical, and massive water conservancy 


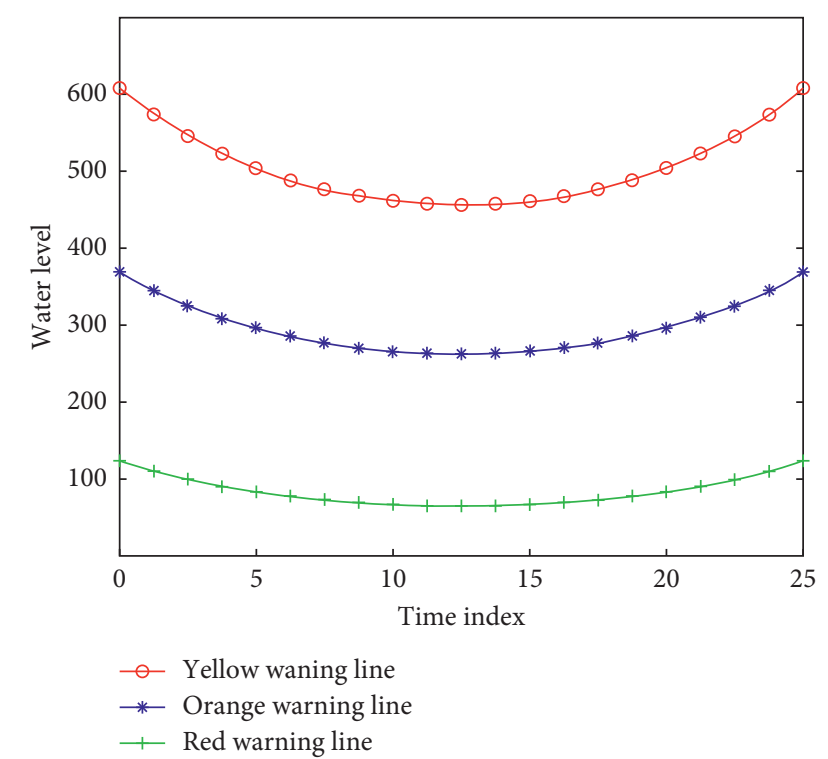

FIgURE 4: Schematic diagram of the location of the water supply warning line of key reservoirs.

data information, which provides decision-making basis and support for leaders.

According to the regression model, the power increment of a server under any workload migrating into a service load with a CPU utilization rate of $\delta$ is $0.4 P_{\text {busy }} * \delta$. But using an empirical model will find that taking $\delta=20 \%$ and $P_{\text {max }}=560 \mathrm{~W}$ as an example, the power increase caused by the new service load when the server is idle is much greater than the performance when the server is under high load, as shown in Figure 5.

According to Figure 5, it is obvious that the power added to the integrated business load of low-load physical machine industry is almost twice that of high-load physical machine industry. From the point of view of physical equipment utilization rate, this phenomenon also conforms to the law of diminishing marginal cost in economics. Therefore, putting the business load on the physical machine with higher CPU utilization can be the basic strategy based on energy efficiency integration.

The storage module analyzes the working condition metadata and stores its associated attributes in an inverted index. An inverted index is a type of index that allows you to search for objects based on their characteristics. Each physical node stores all inverted indexes in pieces as text, with the local pumping station node storing all of the data center's resource information and the scheduling node collecting the data center's important metadata items. Data services assist in the maintenance of data integrity when multiple data sources must be used. Abstract data source, reusability, consistency with logical data model, support for multiple versions of services, value-added features, and single-point interaction are some of the characteristics of services. Centralization, monitoring, version management, data type reuse, data visualization, and access rules can all benefit from the use of data services.

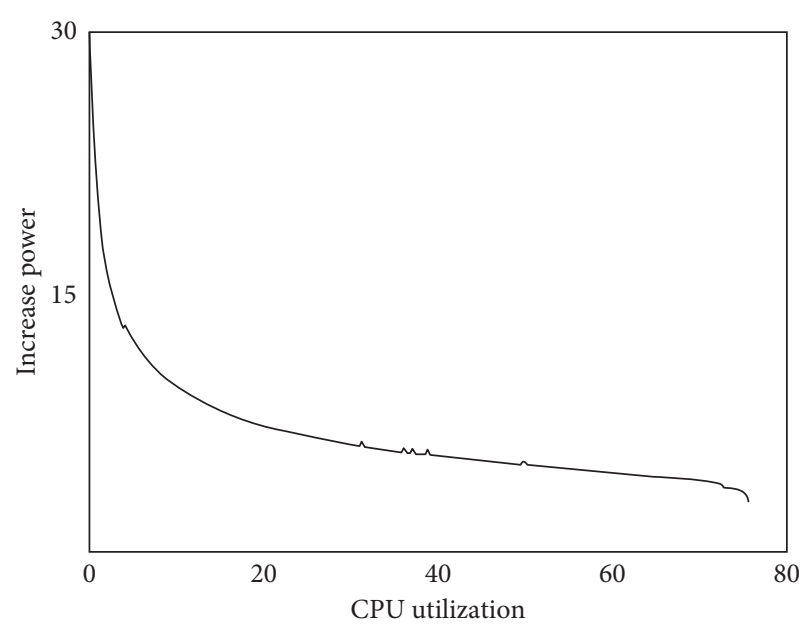

FIgURE 5: Power increase due to migration.

In order to facilitate the algorithm verification, the physical machine/virtual machine model is appropriately simplified in the simulation. Through the simulation, the virtual machines arrive at the data center immediately to form a real-time virtual machine distribution scene. Firstly, the physical machines above the upper threshold are migrated and integrated by using a unified virtual machine selection algorithm. In the integrated scene, compare the integration ability of RP, FFD, and this integration mechanism to low-energy physical machines. Generally, the three integration mechanisms are effective, and sometimes, the performance gap is not too big. Take $(\mathrm{TL}=0.5, \mathrm{TU}=0.9)$ as an example; the change of the number of physical machines that can be evacuated with the load is shown in Figure 6.

The performance of this integration mechanism is clearly superior to the other two, as shown in Figure 6. The data in the data records stored in the data warehouse does not usually change over time, but the data in the data warehouse is constantly increasing; that is, new records are added on a regular basis, so it is time-varying. Data warehouse technology can only better serve business processing and decision-making by addressing the relationship between data warehouse and dynamic and real-time updated water conservancy business database. To enable data sharing, metadata must be extracted, and data resource directories must be established, regardless of whether the centralized integration is physical or logical. Metadata creates multidimensional data directories by linking metadata and resource directories, defining different data resource views in the form of resource directories. To meet the data resource needs of users at different levels, the directory tree of water conservancy object dimension can be duplicated or omitted, the directory tree of organization dimension can be duplicated or omitted, and the directory tree of water conservancy business dimension can be duplicated or omitted.

The form and effect of information expression have an important influence on understanding the connotation of information quickly and accurately. The expression of information can be static numbers, words, tables, and pictures, as well as dynamic images, images, three-dimensional 


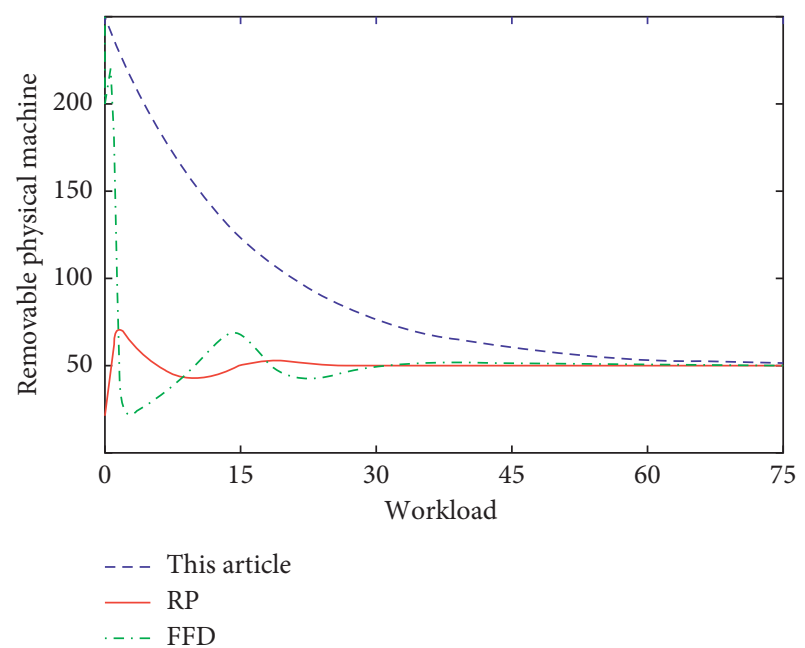

Figure 6: Performance analysis of integration mechanism.

models, virtual scenes, and so on. Visual expression of spatial data, for hydraulic data with spatial attributes, organizes and displays the data through dynamic and interactive $2 \mathrm{D}$ images or $3 \mathrm{D}$ models, which is convenient for users to operate and understand the data. For the hydraulic engineering model, the traditional algorithm and the quality inspection algorithm in this paper are used for quality inspection, respectively. The missing number of 300 key details features is set in the original image obtained through the hydraulic integration model, and the obtained detection accuracy trend is shown in Figure 7.

The vertical axis represents the accuracy of water conservancy project quality inspection, and the horizontal axis represents the order of magnitude of image features that can be used for inspection in water conservancy projects. From the graph, it can be seen that when some key details and characteristics of pixels are missing in the related images of water conservancy projects, the accuracy obtained by using the quality detection algorithm of water conservancy projects in this paper is far greater than that of the traditional intelligent detection algorithm.

Reuse the core water conservancy business such as project management, real-time working conditions, realtime water regime, and the general system functions of e-government, and form a unified data report, data query and map service, etc. These basic applications can be used as services, without considering the integration of the bottom layer, and finally realize the cooperation of water conservancy business applications. The simulation experiment shows that the integration rate of water resources between this method and existing methods is shown in Figure 8.

It can be seen that the integration rate of the two methods tends to be consistent in the early stage, while the integration rate of the method in this paper maintains a high level in the later stage. Overall, the integration rate of this method is better than that of existing methods. Parameterized building family component is an important guarantee for the completeness and accuracy of the information model of water conservancy and hydropower projects including the naming of families and the naming of family

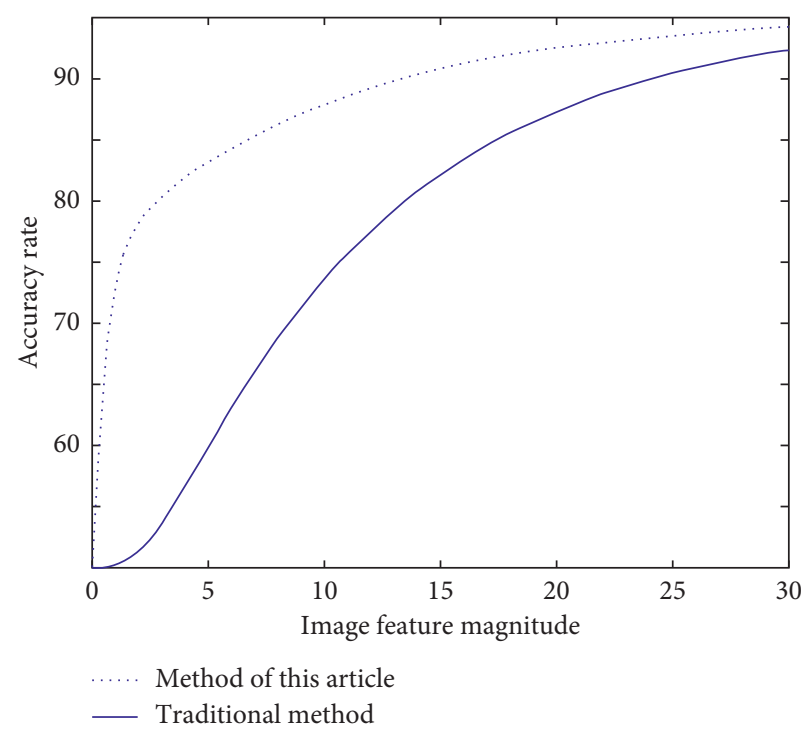

FIgURE 7: Trend chart of detection accuracy of different algorithms.

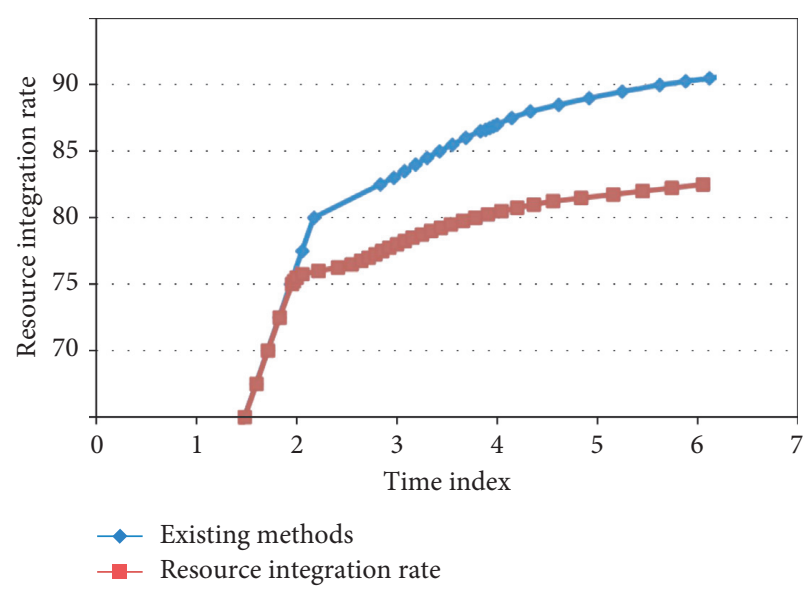

Figure 8: Water resources integration rate.

parameters in standard specifications, and the reasonable family system process, which ensures the standardized description of component information. When applying data warehouse technology to water conservancy business data processing, it is necessary to analyze and study the update frequency and time limit of data stored in data warehouse. The purpose of updating is to meet the specific needs of business processing and decision-making process, and to provide effective and efficient information services as the premise.

The construction of resource integration and sharing platform breaks the traditional thinking, adopts advanced technologies such as data source aggregation, data source synchronization, virtualization, and cloud computing, effectively organizes and manages scattered data of many business systems of different types, forms large amounts of data, establishes a unified data standard and stores it in the data center in a unified way, and realizes various sharing on the basis of ensuring the sharing quality by establishing a reasonable sharing mechanism and process. 


\section{Conclusions}

Water conservancy is the foundation of national economy and social life, which has a bearing on the lifeline of the country since ancient times, so it is necessary to develop the water conservancy industry from a strategic point of view. Cloud computing environment provides a common platform for water conservancy related data and services distributed in different regions and departments. In this paper, the integration and sharing model of water conservancy data resources based on cloud computing is proposed. Among them, the research on key technologies of principal database solves the sustainable utilization of existing systems and data, standardizes the application development of newly built systems using principal database, and effectively solves the problem of "one number and multiple sources." The integration of heterogeneous data can realize the interoperability of distributed heterogeneous data, effectively solve the problem of resource integration, and realize transparent access and resource sharing between different databases and different systems. The visual expression of spatial data solves the process that data can be seen clearly and finally understood and provides decision-making basis for nonprofessional management. Fast data retrieval and discovery can efficiently find the data resources that users are interested in, and solve the key problems in information service system. Simulation results show that this model can integrate and share scattered information resources, optimize resource allocation, and reduce energy consumption. Information cloud system of water conservancy can provide convenient technical support for water conservancy work, significantly improve water conservancy management ability, and promote the transformation from "digital water conservancy" to "smart water conservancy" in China.

\section{Data Availability}

The data used to support the findings of this study are included within the article.

\section{Conflicts of Interest}

All the authors do not have any possible conflicts of interest.

\section{References}

[1] C. $\mathrm{Xu}, \mathrm{K}$. Wang, and M. Guo, "Intelligent resource management in blockchain-based cloud datacenters," IEEE Cloud Computing, vol. 4, no. 6, pp. 50-59, 2018.

[2] B. Li, M. C. Kisacikoglu, C. Liu, N. Singh, and M. ErolKantarci, "Big data analytics for electric vehicle integration in green smart cities," IEEE Communications Magazine, vol. 55, no. 11, pp. 19-25, 2017.

[3] S. Lu, Y. Shang, and Y. Li, "A research on the application of fuzzy iteration clustering in the water conservancy project," Journal of Cleaner Production, vol. 151, no. 5, pp. 356-360, 2017.

[4] L. Zhao, C. Sun, and F. Liu, "Interprovincial two-stage water resource utilization efficiency under environmental constraint and spatial spillover effects in China," Journal of Cleaner Production, vol. 164, no. 10, pp. 715-725, 2017.
[5] S. Namasudra and P. Roy, "Time saving protocol for data accessing in cloud computing," IET Communications, vol. 11, no. 10, pp. 1558-1565, 2017.

[6] Y. Han, G. Wang, J. Yu, C. Liu, Z. Zhang, and M. Zhu, "A service-based approach to traffic sensor data integration and analysis to support community-wide green commute in China," IEEE Transactions on Intelligent Transportation Systems, vol. 17, no. 9, pp. 2648-2657, 2016.

[7] M. Masmoudi, S. B. A. B. Lamine, H. B. Zghal, B. Archimede, and M. H. Karray, "Knowledge hypergraph-based approach for data integration and querying: application to Earth $\mathrm{Ob}-$ servation," Future Generation Computer Systems, vol. 115, no. 1, pp. 720-740, 2021.

[8] Q. Jiang, A. K. Bregt, and L. Kooistra, "Formal and informal environmental sensing data and integration potential: perceptions of citizens and experts," The Science of the Total Environment, vol. 619-620, no. 4, pp. 1133-1142, 2018.

[9] P. Zhang, Q. Zhang, F. Liu et al., "The construction of winter wheat smart water saving irrigation system based on big data and internet of things," International Journal of High Performance Systems Architecture, vol. 7, no. 3, pp. 151-160, 2017.

[10] S. Datta, K. BeTtinger, and M. Snyder, "Corrigendum: secure cloud computing for genomic data," Nature Biotechnology, vol. 34, no. 10, pp. 1072-1591, 2016.

[11] W. Dong and Q. Yang, "Data-driven solution for optimal pumping units scheduling of smart water conservancy," IEEE Internet of Things Journal, vol. 7, no. 3, pp. 1919-1926, 2019.

[12] S. Datta, K. Bettinger, and M. Snyder, "Secure cloud computing for genomic data," Nature Biotechnology, vol. 34, no. 6, pp. 588-591, 2016.

[13] D. Liu, L. Khoukhi, and A. Hafid, "Prediction-based mobile data offloading in mobile cloud computing," IEEE Transactions on Wireless Communications, vol. 17, no. 7, pp. 46604673, 2018.

[14] S. Chen, S. Irving, and L. Peng, "Operational cost optimization for cloud computing data centers using renewable energy," IEEE Systems Journal, vol. 10, no. 4, pp. 1447-1458, 2016.

[15] J. Li, L. Huang, Y. Zhou, S. He, and Z. Ming, "Computation partitioning for mobile cloud computing in a big data environment," IEEE Transactions on Industrial Informatics, vol. 13, no. 4, pp. 2009-2018, 2017.

[16] J. Dong, X. Xia, Z. Zhang, Z. Liu, X. Zhang, and H. Li, "Variations in concentrations and bioavailability of heavy metals in rivers caused by water conservancy projects: insights from water regulation of the Xiaolangdi Reservoir in the Yellow River," Journal of Environmental Sciences, vol. 74, no. 12, pp. 82-90, 2018.

[17] L. Antonio, B. Gianfranco, M. Maurizio, and F. Bruno, “An alignment method for the integration of underwater 3D data captured by a stereovision system and an acoustic camera," Sensors, vol. 16, no. 4, p. 536, 2016.

[18] X. Xu, R. Mo, F. Dai, W. Lin, S. Wan, and W. Dou, "Dynamic resource provisioning with fault tolerance for data-intensive meteorological workflows in cloud," IEEE Transactions on Industrial Informatics, vol. 16, no. 9, pp. 6172-6181, 2020.

[19] D. Liu, X. Qi, QiangFu et al., "A resilience evaluation method for a combined regional agricultural water and soil resource system based on Weighted Mahalanobis distance and a GrayTOPSIS model," Journal of Cleaner Production, vol. 229, no. 8, pp. 667-679, 2019.

[20] A. A. Karabulut, E. Crenna, S. Sala, and A. Udias, "A proposal for integration of the ecosystem-water-food-land-energy (EWFLE) nexus concept into life cycle assessment: a synthesis 
matrix system for food security," Journal of Cleaner Production, vol. 172, no. 4, pp. 3874-3889, 2017.

[21] R. Chaudhary, N. Kumar, and S. Zeadally, "Network service chaining in fog and cloud computing for the $5 \mathrm{G}$ environment: data management and security challenges," IEEE Communications Magazine, vol. 55, no. 11, pp. 114-122, 2017.

[22] F. Pu, Z. Wang, C. Du, W. Zhang, and N. Chen, "Semantic integration of wireless sensor networks into open geospatial consortium sensor observation service to access and share environmental monitoring systems," IET Software, vol. 10, no. 2, pp. 45-53, 2016.

[23] Z. Wu and K. Li, "VBTree: forward secure conjunctive queries over encrypted data for cloud computing," The VLDB journal, vol. 28, no. 1, pp. 25-46, 2019.

[24] L. W. Xiu, W. Li, Z. Bi, Y. Li, and Y. Xu, "Cloud computing in human resource management (HRM) system for small and medium enterprises (SMEs)," International Journal of Advanced Manufacturing Technology, vol. 84, no. 1-4, pp. 485496, 2016.

[25] B Langmead and A. Nellore, "Cloud computing for genomic data analysis and collaboration," Nature Reviews. Genetics, vol. 19, no. 5, pp. 325-326, 2018

[26] J. Sege, M. Ghanem, W. Ahmad, H. Bader, and Y. Rubina, "Distributed data collection and web-based integration for more efficient and informative groundwater pollution risk assessment," Environmental Modelling \& Software, vol. 100, no. 2, pp. 278-290, 2017.

[27] M. R. Ogiela and H. Ko, "Cognitive systems and operations research in big data and cloud computing," Annals of Operations Research, vol. 265, no. 2, pp. 1-4, 2018.

[28] J. Kong, C. Yang, J. Wang et al., "Deep-stacking network approach by multisource data mining for hazardous risk identification in iot-based intelligent food management systems," Computational Intelligence and Neuroscience, vol. 2021, Article ID 1194565, 2021.

[29] M. Nazari Jahantigh, A. Masoud Rahmani, N. Jafari Navimirour, and A. Rezaee, "Integration of Internet of Things and cloud computing: a systematic survey," IET Communications, vol. 14, no. 2, pp. 165-176, 2020. 